\title{
Coordinated X-ray, Ion, and Electron Microanalysis Approach Towards Understanding the Earliest-Formed Solids in the Solar System
}

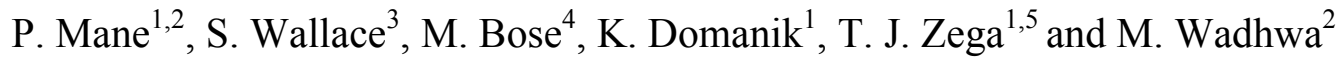 \\ 1. Lunar and Planetary Laboratory, University of Arizona, Tucson, USA. \\ 2. School of Earth and Space Exploration, Arizona State University, Tempe, USA. \\ 3. EDAX, Ametek, Materials Analysis Division, Mahwah, USA. \\ 4. School of Molecular Sciences, Arizona State University, Tempe, USA. \\ 5. Dept. of Materials Science and Engineering, University of Arizona, Tucson, USA.
}

Introduction: Calcium-Aluminum-rich Inclusions (CAIs), hosted in primitive meteorites, are the oldest solids in the Solar System (e.g., [1]). These inclusions are made of highly refractory mineral phases and they are surrounded by a multi-mineralic rim sequence, called Wark-Lovering (WL) rims [2]. The CAIs and their WL rims preserve a record of the earliest Solar System processes [3]. Each mineral layer in the WL rim sequence is typically only a few microns thick (Fig. 1), making a detailed study of their textural, chemical and isotopic characteristics challenging. Because of their fine-grained nature, the mechanisms and timescales of formation of the WL rim sequences are not well understood. We applied a coordinated analytical approach to study these rims, by using X-ray Wavelength Dispersive Spectroscopy (WDS), Energy Dispersive Spectroscopy (EDS), and Electron Back-Scatter Diffraction (EBSD) to determine their composition and microstructure, as well as NanoSIMS (Nano-Secondary Ion Mass Spectrometer) to determine their relative age of formation.

Samples and Methods: A compact type-A CAI from the Northwest Africa (NWA) 5028 CR2 chondrite was analyzed to determine its mineralogy, microtexture, and isotope composition. The mineralogy of this CAI and its WL rim sequence was characterized using the CAMECA SX-100 electron microprobe at University of Arizona and the JEOL JXA-8530F electron microprobe at Arizona State University (ASU). The ${ }^{26} \mathrm{Al}-{ }^{26} \mathrm{Mg}$ systematics were determined using the Cameca Ametek NanoSIMS 50L at ASU. The EBSD analysis was conducted using the FEI Helios NanoLAB 660 focused ion beam scanning electron microscope (FIB-SEM), equipped with EDAX EDS and EBSD detectors, located at the University of Arizona.

Results and Discussion: The interior of the NWA 5028 CAI contains melilite $\left[(\mathrm{Ca}, \mathrm{Na})_{2}(\mathrm{Mg}, \mathrm{Al})(\mathrm{Si}, \mathrm{Al})_{2} \mathrm{O}_{7}\right]$, perovskite $\left[\mathrm{CaTiO}_{3}\right]$, spinel $\left[\mathrm{MgAl}_{2} \mathrm{O}_{4}\right]$, and metal grains [Fe-Ni]. The WL rims consist of an innermost perovskite + hibonite $\left[\mathrm{CaAl}_{12} \mathrm{O}_{19}\right]+$ spinel layer followed by an intermediate melilite layer and an outermost pyroxene $\left[(\mathrm{Mg}, \mathrm{Fe}) \mathrm{SiO}_{3}\right]$ layer (Fig. 1). The melilite in the CAI interior defines an Al-Mg isochron with a canonical initial ${ }^{26} \mathrm{Al} /{ }^{27} \mathrm{Al}$ ratio of $(6.0 \pm 1.1) \times 10^{-5}$, and an initial $\delta^{26} \mathrm{Mg}^{*}$ of $-1.1 \pm 1.3 \%$ (MSWD =2.6). The hibonites in the rim also define a canonical isochron, within the errors, with an initial ${ }^{26} \mathrm{Al} /{ }^{27} \mathrm{Al}$ ratio of $(5.9 \pm 3.2) \times 10^{-5}$, and initial $\delta^{26} \mathrm{Mg}^{*}$ of $-1.3 \pm 3.4 \%$ (MSWD $=2.0$; Fig. 2). The ${ }^{26} \mathrm{Al}-{ }^{26} \mathrm{Mg}$ chronology suggests that the hibonites in the rim layer could not have formed any later than $\sim 640,000$ years after the formation of the CAI interior.

The EBSD analysis shows random crystal orientation of melilite and spinel grains in the interior of the CAI. However, some of the interior melilite grains show evidence for strain and deformation (observed as color variations within a single grain in Fig.4), presumably due to secondary processes. Spinel and melilite grains in the WL rims also show random crystal orientations but do not show evidence for strain 
or deformation, suggesting that the deformation event of interior melilite occurred before the WL rim formation (Figs. 3 and 4). Similar analyses of WL rims conducted previously indicate that the pyroxenes occur as clusters of grains with similar orientation, suggesting a condensation origin [4]. We plan to acquire higher resolution EBSD maps, to understand the grain orientations of pyroxenes in the WL rims around this NWA $5028 \mathrm{CAI}$. Nonetheless, a coordinated microanalysis of CAIs and their WL rims to determine their chemical, isotopic, and textural characteristics can help provide new insights into the timescales and mechanisms of formation of these earliest-formed solids.

\section{References :}

[1] Connelly J. N. et al., Science, 338, (2012), p. 651-655.

[2] Wark D. A. and Lovering J. F., LPSC VII, (1977) p. 95-112.

[3] MacPherson G. J., Meteorites and Cosmochemical Processes, (2014), p. 139-179.

[4] Bolser D. et al., Meteoritics \& Planetary Science, 51, (2016) p. 743-756.

[5] This research supported by National Science Foundation grant number 1531243 and NASA grant numbers NNX15AJ22G and NNX12AL47G. We acknowlegde Paul Wallace at University of Arizona for his help in setting up the EBSD.

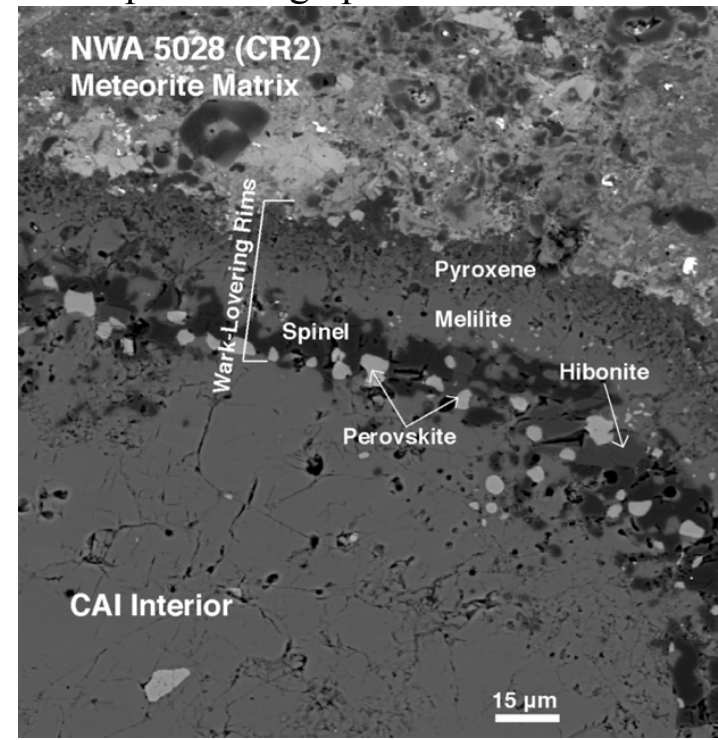

Figure 1. Backscatter electron (BSE) image of the WL rims of the NWA 5028 CAI.

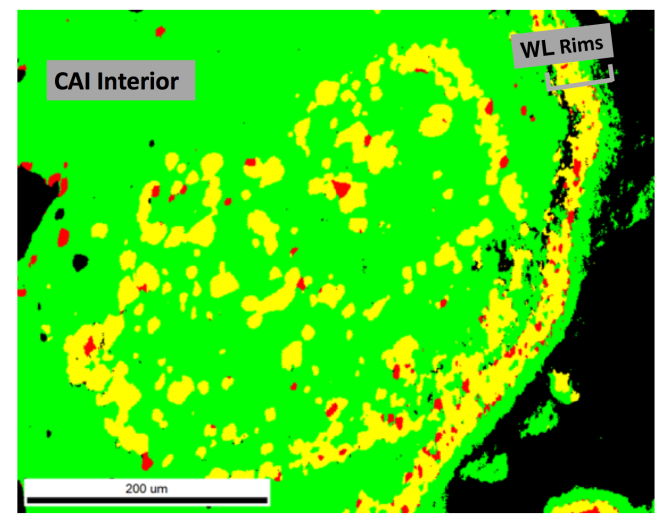

Figure 3. False color composite of mineralogy of the NWA $5028 \mathrm{CAI}$ and its WL rim based on an EDS map. Green = melilite; yellow $=$ spinel; and red $=$ perovskite .

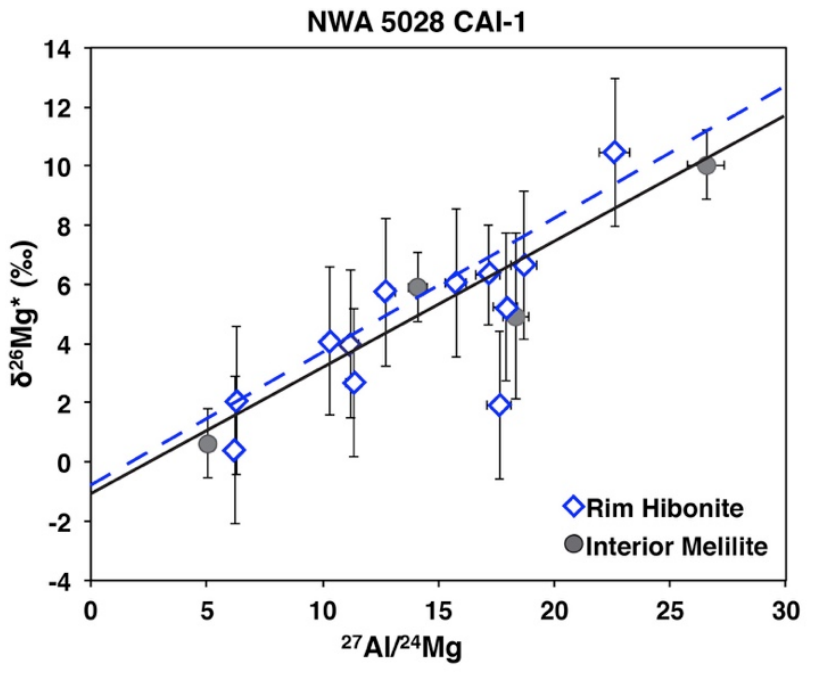

Figure 2. ${ }^{26} \mathrm{Al}-{ }^{26} \mathrm{Mg}$ Systematics of the NWA $5028 \mathrm{CAI}$ and its WL rim, indicating $<640,000$ years of time difference between their formation.

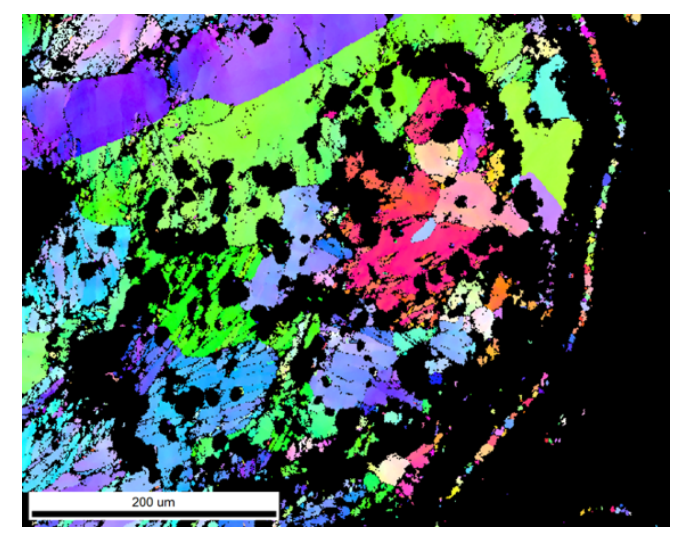

Figure 4. Grain orientation map of melilite, where interior melilite shows strain and deformation and rim melilite shows randomly oriented grains, without significant strain. 